\title{
Um olhar valioso sobre a terra: Sudoeste do Paraná 1930-1940
}

A valuable look about the land: the Southwest of Paraná 1930-1940

\section{Angélica Dalla Rizzarda}

Universidade de Passo Fundo - UPF - Passo Fundo - Rio Grande do Sul - Brasil

Resumo: O Sudoeste do Estado do Paraná foi colonizado, de forma mais intensa, em meados do século $X X$. Boa parte das famílias que migraram para a região fo motivada pela possibilidade de adquirir áreas de terra para o cultivo de cereais, criação de animais e principalmente pela possibilidade de subsistirem por meio do trabalho agrícola. Nesse cenário, a maior parte dos colonos é proveniente do Estado do Rio Grande do Sul, região onde se concentrou boa parte dos imigrantes italianos que vieram para o país durante o final do século XIX e início do Século XX.

As migrações a partir da década de 1930 intensificaram o processo de colonização e exploração das terras sudoestinas, como se denota das principais contribuições econômicas e culturais desses grupos, refletidas na organização do território. Em 1930, com a entrada de Getúlio Vargas ao poder iniciaram-se políticas de povoamento, dentre as quais se destaca a Marcha para o Oeste.

Palavras-chave: Colonização. Terras. Ocupação.

Abstract: The Southwest of the State of Paraná was colonized, in a way more intensely, in the middle of the 20th century. Great part of the families that migrated to the region was motivated by the possibility of acquiring lands' areas for cultivation cereals, animal husbandry and mainly for the possibility of subsisting through agricultural work. In this scenario, great part of the settlers came from the State of Rio Grande do Sul, region where was concentrated great part of the italian immigrants who came to the country during the late 19th and early 20 th centuries.

The migrations from the 1930s intensified the process of colonization and exploration of the southwestern lands, like is showed by the economic and cultural contributions of these groups, reflected in the territory's organization. In 1930, with the entrance of Getúlio Vargas to the power started some settlement politics, one of the most important was called the West March.

Keywords: Colonization. Lands. Occupation. 


\section{Formação do território Paranaense}

Por isso, é importante assinalar que a ideia de região será compreendida aqui como representação do espaço, fazendo parte, portanto de uma produção e de uma invenção imagético-discursiva do real, isto é, o "real" e "seus significados" imaginários instituídos e sendo mobilizados constantemente por um jogo de forças em uma parcela referencial do espaço.

A região, assim, é uma invenção enquanto representação do espaço produzida através de determinadas relações de poder e de saber a elas correspondente, a elas criadas com a intencionalidade de dotar o espaço de sentidos, de valores, de conteúdos, enfim, de função política.

Muitas vezes, a região é uma criação do pesquisador, mas também pode ser forjada, inventada e reinventada a partir de alguns interesses, pois, como aborda Bourdieu (1998):

\begin{abstract}
A região é alvo de disputas, de lutas pelo poder "quase mágico", isto é, do poder simbólico, de fazer crer e ver determinada realidade espacial, ordem e significado. A produção das regiões passa pelo poder simbólico de di-visão que "[...] é, com efeito, esse poder invisível o qual só pode ser exercido com a cumplicidade daqueles que não querem saber que lhe estão sujeitos ou mesmo que o exercem" (BOURDIEU, 1998, p. 8).
\end{abstract}

Contudo, é importante mencionar ainda que a região é normalmente (mas, não exclusivamente) localizada/produzida no interior de um Estado-Nação e, por isso, se constitui enquanto uma escala subnacional. Logo, a região se institui a partir de uma nação, de um território nacional. Historicamente, as regiões podem ser pensadas como emergência de diferenças internas à nação, no tocante ao exercício do poder e da divisão social e territorial do trabalho.

São recortes que surgem a partir de enfrentamentos que ocorrem entre os diferentes grupos sociais no interior da nação. A diferenciação, portanto, é atribuída a um caráter de luta, de disputa de interesses específicos. A região se define, frente ao Estado-Nação, como um "território" contínuo não fragmentado e moldado espacialmente no estilo "colcha de retalhos", em que, especialmente a modernidade capitalista tentou inserir em todos os pontos do planeta.

O povoamento e o desenvolvimento do Sudoeste do Paraná passaram por um processo de evolução, ativados pelas frentes migratórias vindas do Rio Grande do Sul, de Santa Catarina, e do próprio Paraná. Em consequência não só da fertilidade do solo, mas principalmente da quantidade enorme de araucárias existentes, muitas companhias começaram a atuar na região e algumas delas como "grileiras ${ }^{1 "}$. Surgiu a luta entre posseiros e "grileiros".

O processo de colonização, povoamento e exploração econômica, fomentou uma sociedade alicerçada na grande propriedade rural, patriarcalismo, tropeirismo e um modo de vida simples e rústico. A região compreende uma forma de colonização luso-brasileira que conformou um modelo de exploração da terra em grandes fazendas, originárias da distribuição de sesmarias, que deram origem as antigas propriedades rurais de criação de gado ou de invernagem, como o autor Salles destaca:

\begin{abstract}
A origem colonial do Brasil, o período Imperial e o Republicano têm como marca um país agroexportador (até a década de 1960), o que explicita o valor simbólico da propriedade fundiária. A renovação deste lugar (exportador de bens primários) gerou nas elites governantes a defesa quase que sacralizada da premissa do monopólio da terra, do latifúndio como uma estratégia para a formação da nação como podemos ver na construção de diversos discursos ideológicos - "povoamento", "civilização", "colonização", "desenvolvimento", "progresso", etc. - que, em diferentes períodos articulam-se com o "ouro verde" (café) ou o agronegócio contemporâneo. (SALLES, 2011, p.43).
\end{abstract}

De maneira mais ampla e geral, podemos observar o território paranaense em seu povoamento em três fases distintas e organizadas em ordens cronológicas: em meados do século XVII, a primeira fase ganha seu destaque, com características de exploração do território abordado em questão ourífera. A segunda fase, que teve início em 1862 foi marcada pela adentração nas matas e derrubada

\footnotetext{
${ }^{1}$ Pessoa que tenta obter a posse de terras com documentos falsos.
} 
para plantação do café. A terceira e última fase, ganha destaque por ser o período histórico que nos faz referência, e é a base para a realização do nosso estudo e pesquisa, como aborda Wachowicz (1987, p. 5):

\begin{abstract}
A terceira e última etapa, a que trouxe maiores preocupações, correspondeu à ocupação do sudoeste por gaúchos e catarinenses de origem ítalo-germânica, atraídos pela fertilidade dos solos [...], ao tempo do Estado Novo, de Getúlio Vargas.
\end{abstract}

A história da colonização da região Sul do Brasil é considerada por Caio Prado Junior (1973, p. 23) como uma história do comércio europeu, no sentido de exploração econômica, não se caracterizando pela ideia de povoamento. Essa colonização baseava-se apenas no estabelecimento de feitorias comerciais. No Brasil, era preciso criar um povoamento capaz de abastecer o comércio.

\section{Imigração no Brasil: estratégica e geopolítica 1900-1930}

Dessa forma, a ocupação e o povoamento no sentido comercial de exploração deram-se a partir das atividades econômicas realizadas para atender os interesses europeus. Portanto, o início da colonização do Brasil foi um empreendimento marcado pela exploração de matéria-prima, como por exemplo, a madeira, e, em seguida pela exploração agrária em grande escala de monocultura. Este meio de exploração agrícola era a grande riqueza da colônia e foi a partir dela que se ocupou boa parte de território brasileiro.

Entretanto, este meio econômico de ocupação que foi a grande lavoura, não chegou a ocupar grande parte do território oeste, ou do interior. Pois, como a produção era destinada à exportação, as lavouras eram localizadas o mais próximo possível das regiões litorâneas e de fácil acesso aos portos. 0 interior representava uma desvantagem que apenas com o início da pecuária e da mineração, algumas regiões interioranas foram ocupadas.
A imigração foi estratégica e geopolítica, tinha o interesse de povoar as terras da região sul do Brasil. Foi planejada para um processo de substituição não só do trabalho escravo pelo trabalho livre, mas principalmente como uma substituição do negro escravo pelo branco europeu, em um processo de colonização baseado na pequena propriedade.

Conforme destaca Boris Fausto (2004, p. 276), "o Brasil foi um dos países receptores de um grande número de migrantes europeus e asiáticos que vieram para as Américas em busca de oportunidade de trabalho e ascensão social".

Aos poucos, o território paranaense foi sendo ocupado por estrangeiros de diferentes origens. Portugueses, espanhóis, ingleses e seus descendentes e também africanos- cuja presença em nosso território não dependeu de sua vontade. Em meados do século $X X$, o fluxo migratório foi maior $e$ mais diversificado, ou seja, os imigrantes procediam das mais diferentes regiões da Europa para o Paraná.

\section{Figura 1: Migrantes deslocando-se com carroças puxadas a boi em Francisco Beltrão- PR no ano de 1938.}

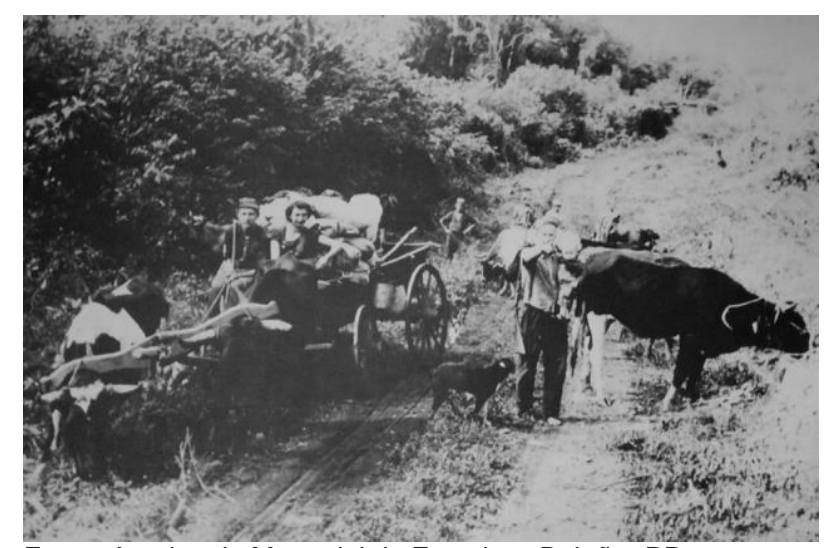

Fonte: Arquivo do Memorial de Francisco Beltrão- PR.

A fotografia acima retratada, mostra com muita clareza a forma que os migrantes deslocavam-se em busca das novas oportunidades de vida. Os seus pertences eram trazidos com carroças movidas com bois, podemos perceber que eram poucos utensílios e a estrada era ainda uma picada.

Além da propaganda exercida sobre as terras férteis e produtivas para a agricultura na região, nas primeiras décadas do século XX, houve a descrição 
do colono que aqui fixou-se, como destaca Stein (2015, p. 34) "clima e solo são caracterizados positivamente, assim como os colonos, os quais são descritos, em quase a sua totalidade, como sadios, "harmoniosos, laboriosos e morigerados"

A política imigratória no Paraná, como no restante do Brasil, foi necessária para povoar regiões do interior, que até então haviam sido habitadas por indígenas e caboclos, e, também, para resolver problemas de falta de mão-de-obra. Desta forma, o governo começou a promover a imigração, dotando o estado de uma política imigratória.

Quando destacamos a imigração para o Brasil, devemos destacar dois pontos estratégicos distintos:

Coexistem no processo imigratório duas atividades distintas: uma, de iniciativa oficial, cujo objetivo era ocupar e povoar as zonas até então não povoadas e distantes, na maior parte das vezes, a área de influência de latifúndio; a outra, de iniciativa particular, estimulada pelo governo, visava a obtenção de braços livres para a grande lavoura, em substituição do braço escravo. (PRADO, 1978, p.78).

Atraídos pela propaganda feita no exterior pelo governo brasileiro, o imigrante acreditava que as terras e o local em si eram o paraíso, com grandes chances de se fazer fortuna, já que a Europa contava com um excedente populacional, e a grande massa humana vivia na miséria em decorrência de guerras, crises econômicas, que geravam desemprego, inflação e muita desigualdade social.

Tão logo as famílias chegavam, eram alojadas em uma sede onde aguardavam que os homens partissem para a floresta, abrissem uma picada desmatassem para realizar o plantio e erguessem um rancho provisório. Isso feito levavam eles suas famílias para ali morarem, até a venda da primeira colheita, quando, mais seguros economicamente, tratavam de erguer a casa definitiva em suas pequenas propriedades. (STECA, 2008, p. 46).

Primeiramente os imigrantes se estabeleceram no Estado do Rio Grande do Sul, onde habitaram as matas, terras que não havia interesse ao setor pecuário. De início, instalaram-se em pequenas propriedades e começaram produzir gêneros alimentícios para o consumo próprio e a venda. Com o uso contínuo da terra e seu esgotamento, às terras gaúchas perderam propriedades produtivas o que levou os colonos a migrarem para Santa Catarina e posteriormente o Paraná.

[...] o minifúndio era expropriado. Seja pelo esgotamento do solo, ou pela utilização de técnicas rudimentares de cultivo, ou ainda pela proliferação de pequenas propriedades cada vez menores, as condições de subsistência interna do minifúndio eram minimizadas, levando o pequeno proprietário e sua família a oferecer trabalho assalariado, quando as condições possibilitavam, ou migrar para outra área do país. (MOURE, 1980, p.113).

Ao analisarmos a História do Paraná em suas fases distintas podemos perceber ainda a colonização da região sudoeste em mais duas fases respectivamente analisadas por Zarth (1997, p.20): o processo de ocupação antes de 1940, chamado de ocupação extensiva de terra, a qual foi caracterizada por uma economia cabocla. A segunda, chamada de ocupação intensiva, refere-se ao efetivo processo de ocupação da região por gaúchos e catarinenses, além dos próprios paranaenses.

Com o crescimento da Campanha Abolicionista e a aprovação progressiva das leis que impediam a possibilidade de submeter pessoas à escravidão, a partir de 1850 houve a necessidade de substituir a mão de obra escrava, incentivando a imigração. Abriu-se espaço para imigrantes pobres, procedentes de vários países europeus como italianos, alemães, poloneses suíços, espanhóis e portugueses.

Como propaganda e atrativo internacional divulgou-se que, os imigrantes seriam distribuídos e assentados em núcleos coloniais em regime de pequena propriedade, em áreas não desbravadas da região Sul do Brasil. Vale observar que o objetivo da imigração era substituir a mão-de-obra escrava, produtora do café e da cana de açúcar no Sudeste e Nordeste do Brasil. Por isso, na prática, levas de imigrantes foram levados para as áreas de grandes lavouras e nelas foram ocupados com vários sistemas de exploração do trabalho. 
Nos núcleos de colonização com regime de pequenas propriedades, formados no Sul do Brasil, com o passar dos anos, surgiria o problema da superpopulação devido ao número elevado de filhos de cada família, e a não possibilidade de novas propriedades para assentar os filhos mais velhos. Estes, quando formavam sua família, necessariamente se deslocavam, procurando outro local para adquirir uma propriedade e poder ter a oportunidade de viver e trabalhar.

O período que podemos destacar como período com maior interesse e ênfase a imigração para o Brasil sob o domínio do latifúndio se concentrou entre 1850 e 1930. Período este ao qual marcou o fim do tráfico negreiro e o início de políticas de povoamento do interior do Brasil as quais visavam um maior desenvolvimento econômico do país.

\section{0 e o grande desenvolvimento da região Sudoeste do Paraná}

O ano de 1930 marcava um novo ponto na imigração, seria a segunda fase de migrações, as quais vinham a ser desenvolvidas dentro do país, principalmente na região Sul do Brasil. Está migração imposta vinha de exigências da sociedade, aonde à mesma vinha sofrendo mudanças continuas. Era tempo de ruptura, novos projetos políticos entrariam em ação com a entrada de Getúlio Vargas ao poder.

Figura 2: Ranchos construídos no início da colonização marcavam a posse da terra.

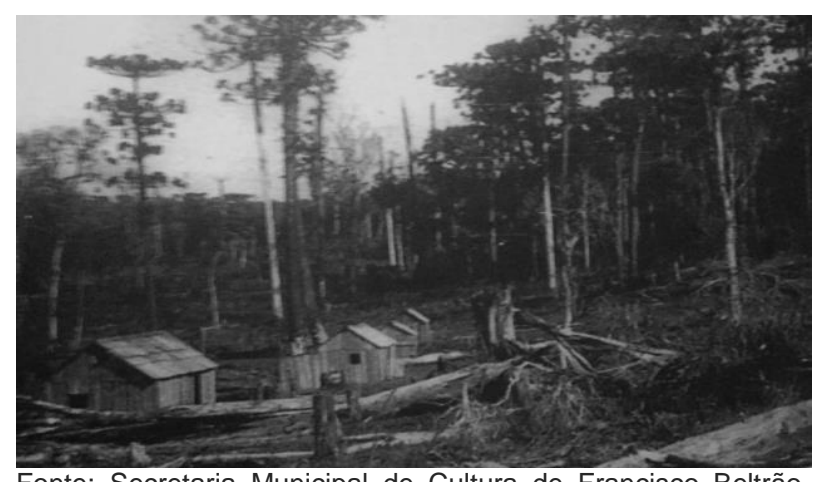

Fonte: Secretaria Municipal de Cultura de Francisco BeltrãoPR, conforme acerca data aproximada de 1932.

$\mathrm{Na}$ imagem acima podemos observar as primeiras casas, em meio à derrubada da mata fechada. As casas eram feitas de madeira e nos primeiros anos de povoamento, foi uma espécie de improviso, pois serviam para abrigar as famílias. Com - passar do tempo e com as adaptações as construções foram melhorando e ficando com condições melhores para se morar.

A ocupação do território deu-se de forma lenta e, sobretudo problemática através dos conflitos. Os estados do Paraná e Santa Catarina também entraram em conflito pela região. Os conflitos pela posse de terra envolveram também a CIA. de Estradas de Ferro São Paulo-Rio Grande, a CITLA (Clevelândia Industrial e Territorial LTDA), o Governo Federal, o Governo do Paraná e os Posseiros.

Outros dois fatores foram relevantes para o desenvolvimento da nova província: a imigração e o surto agrícola. O desenvolvimento da agricultura apresentou um novo elemento no cenário do campo, o colono imigrante, que dominou áreas de matas e campos, cultivando grandes terrenos, ocupando cada vez mais terras.

No início do século $X X$ existiam poucos povoados na região. Um deles, denominado Canela, teve início em 1919, sendo elevada à categoria de Distrito Judiciário em 1927, com a denominação de Bom Retiro, onde se encontra hoje a sede do Município de Pato Branco. Os povoados de Barracão e Santo Antônio na fronteira da Argentina, outro núcleo populacional, era Campo-Erê, na divisa entre - Paraná e Santa Catarina. Afora esses povoados existiam alguns moradores dispersos, inclusive fugitivos da Justiça.

Temos em construção histórica, o destaque do vazio demográfico (um baixo número de pessoas habitavam o local) no início do século $X X$ na região sudoestina. Não podemos deixar de abordar e destacar os indígenas que aqui já habitavam e exploravam os bens naturais. Alguns autores e pesquisadores deixam este período sem destaque, pois à população existente não era em um número elevado. Como aborda Wachowicz (1987, p.55):

No início do século $X X$, o sudoeste paranaense, de Mariópolis até a fronteira argentina, continuava a ser um imenso vazio 
demográfico. Sua população atingia apenas 3.000 habitantes. [...] No início da década de 1920 a população alcançava a 10.720 pessoas.

A colonização oficial do sudoeste do Paraná começou no final dos anos 1920 e início dos anos 1930, analisaremos sob a perspectiva da política do governo do presidente Getúlio Vargas, que defendia a manutenção e consolidação das fronteiras nacionais, para tanto estimulou o processo de ocupação e colonização das faixas de fronteira com países vizinhos.

As medidas como doação de terras e o discurso da terra prometida, da riqueza fácil e da melhoria de vida atraíram um grande número de colonos, especialmente das áreas coloniais do Rio Grande do Sul e Santa Catarina, além de pequenos proprietários e trabalhadores que vinham em busca de novas oportunidades.

As bases legais para a organização dos Núcleos Coloniais foram fixadas pelo Decreto Lei noㅡ 2.009, de 09 de fevereiro de 1940. O referido decreto definiu os núcleos coloniais como uma reunião de lotes medidos e demarcados, criados pela União, Estados, Municípios e por empresas particulares a fim de acolher agricultores, em pequenas propriedades rurais.

\section{A agricultura: a base econômica a partir de 1930}

O entendimento dos conflitos sociais no campo, ocorridos e que ainda ocorrem em boa parte do território paranaense, envolvendo particularmente suas origens e suas razões passa, primeiro, pelo entendimento do processo histórico envolvendo os mecanismos que marcaram o acesso à terra na fase da ocupação pioneira.

Ao analisar a questão da posse de terra na ótica dos conflitos, tem-se a economia como forma de sustentação das famílias que estavam se aculturando em novas terras. Tal processo necessitou de uma base, na qual as famílias pudessem se instalar e dar sequência em seu cotidiano diário, a base econômica da população que migrou em direção ao sudoeste era uma agricultura de subsistência.

A agricultura que era de subsistência, com o decorrer do tempo, passou a se desenvolver de uma forma ampla de crescimento. Foram adquiridas novas técnicas perante ela, novas tecnologias, novos produtos, novos avanços e até mesmo experiências vivenciadas em anos anteriores serviram de base na agricultura para os colonos.

A produção agrícola regional pode ser dividida em duas etapas básicas. Uma agricultura de caráter local, na qual o comércio era reduzido e voltado para a subsistência das famílias. Nos dois setores básicos da economia - pecuária e extrativismo, havia quase autossuficiência agrícola. Num segundo momento, a agricultura recebeu significativo impulso e passou a conquistar lugar de grande importância na economia local.

O nosso agricultor, depois de derrubar a machado e foice o mato, deixam-no secar e então prendem-lhe fogo, logo que caem as primeiras chuvas, fazem a plantação, cavando a terra com um pau chamado saraquá, depositam nesse buraco a semente que trazem consigo no embornal a tiracolo, que chamam samblará, feito isso a roça não demanda mais trabalho senão no tempo da colheita. (FOWERAKER, 1982, p. 54, grifo da autora).

Paralelamente à agricultura de primeira instância de forma arcaica e que com o passar dos anos passa a adquirir novas formas, a existência de grandes áreas agricultáveis devolutas ou passíveis de compra por preços baixos, trouxe à região um forte contingente de agricultores provenientes das áreas agrícolas onde já havia se esgotado a fertilidade do solo.

Dois fatores, o aumento populacional e o acesso ao mercado consumidor, permitiram grande expansão da produção agrícola regional, sobretudo em termos quantitativos, pela incorporação de florestas virgens e pelo maior número de trabalhadores na agricultura.

O plantar e o colher eram sempre uma aventura que para o agricultor poderia trazer lucros ou prejuízos, o período do plantio era sempre uma 
aventura e o final era incerto. Na ausência de armazenamento, as adversidades climáticas colocavam em difícil situação a armazenagem e o resultado final era a venda dos produtos com um baixo valor no mercado. Plantar sempre era um risco que os agricultores exerciam anualmente. $O$ resultado das colheitas dependia diretamente do clima que iria prevalecer.

A partir de 1930, as mudanças na economia rural brasileira dispersaram milhares de trabalhadores agrícolas, exigindo que parte deles se interiorizasse pelo país em busca de terras virgens nas várias fronteiras agrícolas, para consolidar uma agricultura e uma pecuária em expansão.

Deste modo, as migrações se efetivaram e os modos de produção ganharam maior ênfase na região. O cenário estava sendo construído pelos colonos/ posseiros e posteriormente seria reivindicado o que era de valor deles, a terra.

O Sudoeste do Paraná foi ocupado e organizado como lugar de oportunidades para o acesso à terra e de reprodução de um modo de vida assentado na pequena propriedade rural, com atividades agrícolas e trabalho familiar, bem como da construção de pequenas e pacatas comunidades.

À medida que os primeiros migrantes foram recebendo e/ou adquirindo lotes e se fixando na região, estes enviavam notícias aos parentes e amigos contando das peculiaridades do território, das novas oportunidades de trabalho e da aquisição de terras, incentivando outras pessoas a migrarem para a região. Esse processo ocorre através das redes, mais especificamente de relações sociais.

A mobilidade influencia no território e na construção da identidade, a partir das novas territorialidades emergentes. Um determinado indivíduo ou grupo social constrói no seu cotidiano diferentes relações de comunicação com o território de origem e também de destino, entre migrantes.

\section{Considerações finais}

Podemos concluir que houve um grande incentivo à migração de pessoas do Rio Grande do
Sul e de Santa Catarina para o Sudoeste do Paraná no início do século XX. Está imigração vinha como um ponto principal para o desenvolvimento da região, pois era necessário povoar e explorar os bens naturais, como a erva mate e a indústria madeireira.

Ganhou ênfase o processo imigratório neste contexto, pois no período em que estava ocorrendo à disputa entre as terras paranaenses e catarinenses iniciava-se a imigração e colonização nos território do oeste e sudoeste do Paraná, os quais estavam sobre zona de litígio.

Assim a região sudoeste do Paraná nasce a partir de interesses de conquistas de terras, ocupação de território, com uma frente capitalista desenvolvimentista sem compromissos e preocupações com o lugar ocupado.

Podemos observar também as condições do deslocamento dos migrantes, os quais faziam longas viagens onde o meio de transporte era a carroça movida à força animal, os seus pertences também eram poucos e muitas vezes eram perdidos ou deixados no meio da viagem para facilitar o deslocamento.

A colonização desta região se deu por famílias que viam na migração para o Sudoeste do Paraná o sonho de ter sua própria terra, sendo esse o modelo de apropriação. Foram criados projetos os quais ampararam estas pessoas em terras sudoestinas.

\section{Referências}

BOURDIEU, Pierre. O poder simbólico. 2. ed. Lisboa; Rio de Janeiro: Bertrand Brasil, 1998.

Decreto - Lei № 2.009 de 09 de Fevereiro de 1940. Nova organização aos núcleos coloniais. Disponível em: http://www2.camara.leg.br/legin/fed/declei/1940 -1949/decreto-lei-2009-9-fevereiro-1940-

411911-publicacaooriginal-1-pe.html. Acesso: 07/08/2017.

FAUSTO, Boris. História do Brasil. São Paulo: Editora da Universidade de São Paulo, 2004.

FOWERAKER, Joe. A luta pela terra. Rio de Janeiro: Zahar, 1982 
MOURE, Telmo. A inserção da economia imigrante na economia gaúcha. Porto Alegre: Mercado Aberto, 1980.

PRADO, Caio Jr. Formação do Brasil contemporâneo. São Paulo: Ed. Brasiliense, 1973.

SALLES, Jefferson. De Oliveira. Institucionalização da propriedade fundiária e conflitos agrários no município do Pinhão. 2013, f. 129. Dissertação (Mestrado em Sociologia). Setor de Ciência Humanas, Letras e Artes - UFPR. Curitiba, 2013, p. 43.

STECA, Lucinéia Cunha. História do Paraná: do século XVI à década de 1950. Londrina: ed. UEL, 2008.

ZARTH, Paulo Afonso. História agrária do Planalto gaúcho 1850-1920. ljuí/RS: UNIJUÍ, 1997.

WACHOWICZ, Ruy Christovam. Paraná, Sudoeste: ocupação e colonização. Curitiba: ed.Vicentina, 1987. 